\title{
Investigating Physiological and Morphological Mechanisms of Drought Tolerance in Wheat (Triticum aestivum L.) Lines with 1RS Translocation
}

\author{
David Karki' ${ }^{1}$, William Wyant III'1, William A. Berzonsky², Karl D. Glover ${ }^{1}$ \\ ${ }^{1}$ Plant Science Department, South Dakota State University, Brookings, USA \\ ${ }^{2}$ Formerly Plant Science Department, South Dakota State University, Brookings, USA \\ Email: David.Karki@sdstate.edu
}

Received 20 April 2014; revised 19 May 2014; accepted 12 June 2014

Copyright (C) 2014 by authors and Scientific Research Publishing Inc.

This work is licensed under the Creative Commons Attribution International License (CC BY). http://creativecommons.org/licenses/by/4.0/

(c) (i) Open Access

\section{Abstract}

Rye (Secale cereale L.) chromosome translocation is reported to enhance yield attributes in common wheat (Triticum aestivum L.). We used 1RS translocations within the spring wheat cultivar "Pavon76" to measure and identify the translocation that is suitable to withstand moisture stress conditions without significant loss in yield potential. Four lines were grown under two water regimes in greenhouse environment in 2011 and 2012. The rye translocation increased root and shoot biomass in some cases, reduced plant height, and delayed maturity in some cases. The 1RS.1BL translocation produced the highest grain yield associated with the lowest root and shoot biomass under both well watered and water stressed conditions. Root and shoot biomass were recorded the highest for 1RS.1AL under well watered condition. However it produced the least biomass for both traits under water stressed conditions. In most cases, lines were not statistically differentiated for seminal root angle, abscisic acid concentration, water use efficiency, and grain yield. Results from our study show that the 1RS.1BL translocation is more suited to produce high grain yield under moisture limiting conditions.

\section{Keywords}

Wheat, Rye, Translocation, Chromosome, Water Regime

\section{Introduction}

Drought is considered the most widespread limitation to wheat (Triticum aestivum L.) productivity in non-irri-

How to cite this paper: Karki, D., Wyant III, W., Berzonsky, W.A. and Glover, K.D. (2014) Investigating Physiological and Morphological Mechanisms of Drought Tolerance in Wheat (Triticum aestivum L.) Lines with 1RS Translocation. American Journal of Plant Sciences, 5, 1936-1944. http://dx.doi.org/10.4236/ajps.2014.513207 
gated production systems [1]. Under water deficit conditions, plants ability to produce sufficient above and below ground biomass is highly reduced, which consequently affects the grain yield [2] [3]. Enhanced plant root can maximize extraction of soil moisture during drought conditions [4]. Rye (Secale cereale L.), one of the temperate cereals is known for its highly developed root system and wide adaptation during abiotic stresses such as drought, heat, and cold conditions, but its production is limited due to inferior grain quality when compared with common bread wheat [5] [6]. Introgression of rye genetic material into wheat has provided wide variability in wheat breeding programs [7]. Wheat lines containing a segment of short arm of rye choromosome-1 (1RS) on the long-arm of chromosome-1 (1AL, 1BL or 1DL) in the form of translocation have been identified to provide better grain yield, disease resistance, and wider adaptation than the lines without translocations [8]-[10]. Understanding physiological and morphological mechanisms of drought tolerance in wheat cultivars with 1RS translocation could help plant breeders to develop cultivars with improved adaptation to drought.

Villareal et al. [8] used recombinant inbred lines created by crossing spring and winter wheat developed by Texas A \& M University and International Wheat and Maize Improvement Center (CIMMYT) to study the effect of 1RS.1AL translocation on their agronomic performance under optimum and limited water environments. In this study, the 1RS.1AL translocation showed higher grain yield, above ground biomass, and spikes per unit area under normal growing conditions [8]. The ability of translocation lines to perform better in moisture stressed conditions may be due to root system functionality. In a comprehensive review, [11] highlighted the importance of root architecture and density to improve crop yield potential under water limiting conditions. Manschadi et al. [18] reported that drought tolerant wheat had compact root, uniform rooting pattern, greater root length at depth, and narrower seminal root axes angle. The study also reported that cultivar "SeriM82", expressing narrower seminal root angle, produced up to $14.5 \%$ more grain in water-deficit environments than cultivars adapted to environments with optimum moisture levels. Ehdaie et al. [10] used 1RS, 2RS, and 2RL translocations on "Pavon76" and "Chinese Spring" background to study their effects on root biomass, water-use efficiency and agronomic traits. They reported that the 1RS translocation increased root biomass with positive correlation of root biomass with grain yield whereas, the 2RS and 2RL translocations were not found to be significantly associated with either above or the belowground characteristics [10]. Among 1RS translocations, 1RS.1AL and 1RS.1DL showed increased grain yield and enhanced root system when exposed to stress environments [10]. In another study, Ehdaie et al. [12] used identical genetic materials and reported similar grain yield for non-translocation line under moisture stress conditions which was due to genes influencing the adaptive phenotypic plasticity of the root system of spring wheat line Pavon76. The adaptive plasticity can be a result of plants' physiological response to contrasting growing conditions. For instance, in maize (Zea mays L.), as an adaptive response, both root and leaf abscisic acid (ABA) levels were found to be elevated when exposed to drought conditions [13] [14].

Studies conducted with specific rye chromosome translocations have shown varying results. Gray bosch et al. [15] did not notice any significant effects of 1RS.1AL translocation on grain yield of hard red winter wheat lines. McKendry et al. [16] studied 1RS.1BL translocation in 40 F-9 derived sister lines of two soft red winter wheats grown at diverse Missouri wheat growing regions and reported non-significant effect on grain yield, kernel weight, spikelet per head, grain per spikelet, and harvest index (HI). On the other hand, Villareal et al. [17] [18] used the same chromosomal translocation and found significant positive effects of the translocation on grain yield and test weight. These studies show that rye-wheat translocations can demonstrate varied response for different above and below ground characteristics when introgressed into different genetic background. Objectives of our study were: 1) to determine seminal root angle, ABA concentration, and yield related traits for $1 \mathrm{AL}, 1 \mathrm{BL}$, and 1DL wheat-rye translocations on cultivar Pavon76; 2) to identify wheat-rye chromosomal translocation that is more suited for moisture stress conditions.

\section{Materials and Methods}

\subsection{Plant Material}

Cultivar Pavon76, a white spring wheat was developed by International Maize and Wheat Improvement Center (CIMMYT) in 1976 for production under irrigated system. Chromosomal translocations of short arm of rye chromosome 1 (i.e. 1RS) with long arm of chromosome group 1 in Pavon76 were created by Lukaszewski [19] producing translocation lines 1RS.1AL, 1RS.1BL, and 1RS.1DL. These translocation lines and cultivar Pavon76 with normal chromosomes were used in our greenhouse study conducted in fall of 2011 and 2012. In the second 
year, plants were grown in the dome shaped heated plastic house (hoop house) so that other on-going projects within the breeding program could be better arranged in the greenhouse used in the first year. In order to be used in this study, these plant materials were provided by Adam J. Lukaszewski at University of California, Riverside.

\subsection{Root Angle Study}

Root observation box slightly modified from the one that is described by Bengough et al. [20] was used to determine seminal root angle. The observation box was constructed using two glass plates measuring $30 \mathrm{~cm} \times 210$ $\mathrm{cm} \times 0.8 \mathrm{~cm}$. A moist blotting paper was laid on one of the glass plates to serve as platform for germinating seeds. Ten seeds of each line were surface sterilized in $75 \%$ alcohol solution and then attached to the blotting paper using 2\% Phytagel (Sigma-Aldrich, Inc., St. Louis, MO, USA) within each observation box. Acrylic spacers of $0.5 \mathrm{~cm}$ thick were used to separate two glass plates so that seeds can germinate and grow on the blotting paper. Metal binding clips ( $5 \mathrm{~cm}$ wide) were used to clamp two glass sheets. On the eighth day, observation boxes were scanned on a HP Scanjet 4670 flatbed scanner (HP, Palo Alto, California, USA) and the angle between two outermost seminal roots (first pair of seminal roots) was measured using a protractor.

\subsection{Phenotypic Measurements}

Five healthy seedlings of each line selected from the root angle study were planted into pots filled with sterilized potting mixture of $1 / 3$ sand, soil and commercial potting mix "Sunshine \#1" (sphagnum peat moss, coarse perlite, starter nutrient charge with Gypsum, dolomitic limestone) and grown in the greenhouse at South Dakota State University. Temperature in the greenhouse was maintained at $\sim 25^{\circ} \mathrm{C}$. Each pot contained one seedling. All pots were placed within empty $2 \mathrm{~L}$ buckets to hold the leached water. Pots were arranged in randomized complete block (RCB) design separated into 2 water treatments; well-watered and water stressed. Starting on the day of transplant, $500 \mathrm{ml}$ (496 g) water was applied to all pots every 3 - 4 days until booting stage or Feekes growth scale 10 as described by Large [21]. Following booting stage, the watering was continued in similar fashion for plants in the well watered treatment, whereas the drought treatment received only half the amount ( $248 \mathrm{~g}$ ) every 4 - 5 days until maturity. Eight control pots without seedlings were planted to estimate the total amount of water used by plants during the growing season. Phenological data was recorded for plant height, tiller plant ${ }^{-1}$, spike plant $^{-1}$, spike length, dry shoot biomass, dry root biomass, grain weight, and days to heading. For the 2012 study, measurements of spike length, tiller plant ${ }^{-1}$, and days to heading were discontinued due to minimal variations among lines grown in 2011. At maturity, plants in each pot were cut at the soil level to assess root and shoot biomass. Shoot biomass was measured before threshing spikes from each pot. Roots from each line were washed and dried at $140^{\circ} \mathrm{C}$ for 48 hours, before measuring dry root biomass. Water use efficiency (WUE), stress tolerance index (STI), and harvest index (HI) were calculated for tested lines grown in each water regime using following formulae:

WUE $=$ BiomassT $/ \Psi T-(\Psi$ evap $+\Psi L)[22]$ where,

Biomass $\mathrm{T}=$ total dry biomass (root + shoot) in $\mathrm{g}$,

$\Psi \mathrm{T}-(\Psi$ evap $+\Psi \mathrm{L})=$ total water used in $\mathrm{kg}($ i.e. $\Psi \mathrm{T}=$ total water applied, $\Psi$ evap $=$ total water evaporated, $\Psi \mathrm{L}$ $=$ total water leached)

$\mathrm{STI}=(\mathrm{Yp})(\mathrm{Ys}) /(\overline{\mathrm{Y} p})^{2}[22]$ where,

$\mathrm{Yp}=$ line grain weight $(\mathrm{g})$ in well water environment

Ys = line grain weight (g) in water stress environment

$\bar{Y} p=$ mean grain weight $(g)$ in well water environment over all lines

$\mathrm{HI}=\mathrm{GW} / \mathrm{A}_{\text {bio }}$ where,

$\mathrm{GW}=$ grain weight

$\mathrm{A}_{\text {bio }}=$ dry above ground biomass.

\subsection{Abscisic Acid Content (ABA)}

Leaf ABA content was measured for all lines tested over both years using Liquid Chromatography-Mass Spectrometry method (LC/MS). Leaf samples (1.5 g) obtained from middle section of fully grown healthy leaves were sent to Proteomics and Mass Spectrometry at Donald Danforth Plant Science Center, St Louis, MO for 
ABA analysis. In 2011, the ABA assay was conducted in duplicates for each line within each treatment, whereas in 2012 growing season, the assay was run for three leaf samples for each line within each treatment.

\subsection{Statistical Analysis}

All data measured in both trials were subjected to analysis of variance (ANOVA) using PROC GLM in SAS statistical software [23]. Significance of effects was tested at $P>0.05$. Due to significant year-by-treatment effects for all measured traits except ABA content, analyses hereby are presented separately for different growing years (data not shown). This may be due to contrasting weather (such as natural light) when plants were growing or it may be due to the differences between the greenhouses used in two years.

\section{Results and Discussion}

\subsection{Effects of Water Regimes}

Separate ANOVA was conducted for each experiment carried out in 2011 and 2012. The water regime had highly significant effects on all traits measure in both years except for plant height in 2012 (Table 1). The effect of lines used in this study had significant effect on dry root and dry shoot biomass in 2011 whereas in 2012 the line effect was non-significant for all traits. Interaction of line-by-treatment showed significant impact for dry root in both 2011 and 2012 whereas only spike per plant had significant line effect in 2012 (Table 1). Significance level of water regime was higher than that of line or the interaction of line with water regime (Table 1).

\subsection{Seminal Root Angle}

Seminal root angle was measure in only 2011 trial. The mean seminal root angles were measure from all seeds that germinated for each line. Only line Pavon76 had all ten seeds germinated and were developed enough to measure the angles. The 1RS.1AL, 1RS.1BL and 1RS.1DL had eight, seven, and six readings taken respectively. The mean seminal root angle ranged from $81.71^{\circ}$ (1RS.1BL) to $104.4^{\circ}$ (1RS.1AL) and the lines were not statistically different $\left(\mathrm{LSD}_{0.05}\right)$ which may be due to variations within lines across replications (Table 2). In some

Table 1. Analysis of variance showing effect of genotype (line), water treatment (trt) and their interaction for traits measured in 2011 and 2012 greenhouse studies for Pavon76 and its rye translocation lines.

\begin{tabular}{|c|c|c|c|c|c|c|}
\hline \multirow[t]{2}{*}{ Traits } & \multicolumn{3}{|c|}{2011} & \multicolumn{3}{|c|}{2012} \\
\hline & Line & Trt & Line $\times$ Trt & Line & Trt & Line $\times$ Trt \\
\hline Plant Height (cm) & 11.18 & $1025.82^{* * *}$ & 17.28 & 31.18 & 37.25 & 27.26 \\
\hline Spike plant $^{-1}$ & 1.03 & $61.36^{* * *}$ & 0.28 & 0.3 & $216.23^{* * *}$ & $23.36^{* *}$ \\
\hline Dry Root (g) & $0.86^{* * *}$ & $1.41^{* * *}$ & $0.35^{*}$ & 0.22 & $18.98^{* * *}$ & $0.97^{*}$ \\
\hline Dry shoot (g) & $5.82^{*}$ & $728.04^{* * *}$ & 2.83 & 3.16 & $427.06^{* * *}$ & 7.19 \\
\hline Yield (g) & 0.21 & $6.40^{* * *}$ & 0.34 & 1.16 & $21.61^{* * *}$ & 0.54 \\
\hline Harvest Index & 55.93 & $313.44^{* * *}$ & 44.78 & 142.4 & $656.42^{* *}$ & 50.03 \\
\hline $\mathrm{ABA}\left(\mathrm{ng} \mathrm{g}^{-1}\right)$ & 431.44 & $2711.19^{* *}$ & 657.81 & 2943.36 & $6817.54^{*}$ & 1703.4 \\
\hline
\end{tabular}

$*^{* *},{ }^{* * *}=$ Statistical significance level at $0.05,0.01$, and 0.001 probability level.

Table 2. Mean and range of seminal root angle measure for Pavon76 and its rye translocation lines.

\begin{tabular}{|c|c|c|c|c|}
\hline Line & Frequency & Min & Max & Mean \\
\hline Pavon76 & 10 & 48 & 119 & 91.4 \\
\hline $1 \mathrm{AL}$ & 8 & 59 & 136 & 104.38 \\
\hline $1 \mathrm{BL}$ & 7 & 35 & 140 & 81.71 \\
\hline 1DL & 6 & 87 & 112 & 96.5 \\
\hline $\mathrm{LSD}_{0.05}$ & & & & NS \\
\hline
\end{tabular}

$\mathrm{LSD}_{0.05}=$ Differences between the values within the mean column that are narrower than LSD are not statistically different at 0.05 probability level. NS = non-significant at 0.05 probability level. 
instances, angles differences among the reading were more than double within the same line. Root architecture is considered as one of the major attributes of drought adaptive crops. We measured angle between the two outermost seminal roots during first pair seminal root phase. Previous studies on seminal root angle reported lower values, which could be due to their measurement of the angle between primary seminal root and one of the first pair of seminal roots and also using entirely different genotypes than the ones used in our study [24] [25]. Further, Manschadi et al. [1] reported that a narrower seminal root angle was associated with higher grain yield in moisture limiting condition. In our study, narrowest seminal root angle was recorded for 1RS.1BL which yielded better than other lines tested in this study (Table 3). We conducted correlation analysis of seminal root angle with other measured traits and did not find significant correlation with any of the traits measured. Christopher et al. [26] reported similar results to ours where they did not observe any significant correlation between grain yield and root angle, however, they found weak correlation with the seminal root number. More study is needed to confirm the association of root architecture and seed yield in bread wheat.

\subsection{Phenological Traits}

Tiller plant ${ }^{-1}$, spike length, days to heading, and WUE were measured only in the 2011 trial. The measurement of these traits was discontinued in 2012 due to lack of statistical significance among lines for these traits when grown under two water regimes in the study. Average tiller plant ${ }^{-1}$ ranged from 7.2 (Pavon76 and 1RS.1AL) to 8.75 (1RS.1DL) and 6.6 (1RS.1BL) to 8.25 (1RS.1DL) for well watered and water stressed treatments respectively. The differences between WUE of lines used in this study were very narrow. The difference between the most and the least efficient lines was higher in water stressed treatment (i.e. $0.77 \mathrm{~g}$ biomass per kilogram of water). For spike length, the 1RS.1AL produced the longest spikes within well water treatment, whereas Pavon76 had the longest spikes in drought treatment. In both treatments 1RS.1DL produced the shortest spikes, however, the values were not statistically significant (Table 3). Maturity is consistent among the tested lines in both treatments with 1RS.1BL being the earliest maturing and 1RS.1AL the latest. Plant height, spike per plant, total dry biomass (root and shoot), yield, harvest index, and ABA content were measured in both experiment experimental years. Differences in plant height were observed between Pavon76 and its translocation lines. In 2011 well water treatment, lines showed significant differences for plant height, dry root biomass, harvest index, spike length, and days to heading, whereas in the water stress treatment, only spike per plant was observed to be

Table 3. Mean and Least Significant Difference (LSD) values of all traits measured in 2011 for Pavon76 and its rye translocation lines grown under well-water and water stress (drought) conditions.

\begin{tabular}{|c|c|c|c|c|c|c|c|c|c|c|}
\hline \multirow{3}{*}{ Trait } & \multicolumn{10}{|c|}{2011} \\
\hline & \multicolumn{5}{|c|}{ Well-Watered } & \multicolumn{5}{|c|}{ Drought } \\
\hline & Pavon76 & 1AL & 1BL & 1DL & $\mathbf{L S D}_{0.05}$ & Pavon76 & $1 \mathrm{AL}$ & 1BL & 1DL & $\mathbf{L S D}_{0.05}$ \\
\hline Plant Height (cm) & 51.40 & 47.70 & 52.50 & 48.33 & 3.58 & 40.33 & 40.00 & 38.40 & 38.50 & NS \\
\hline Spike plant ${ }^{-1}$ & 5.00 & 5.20 & 4.20 & 5.67 & NS & 2.00 & 2.40 & 2.00 & 2.50 & 0.57 \\
\hline Dry Root (g) & 51.40 & 47.70 & 0.70 & 1.05 & 0.59 & 0.80 & 0.82 & 0.48 & 0.61 & NS \\
\hline Dry shoot (g) & 14.59 & 16.09 & 13.50 & 14.20 & NS & 5.69 & 5.70 & 5.26 & 5.04 & NS \\
\hline Yield (g) & 1.63 & 2.00 & 2.00 & 1.56 & NS & 1.17 & 0.69 & 1.02 & 0.86 & NS \\
\hline Harvest Index & 10.90 & 12.36 & 14.80 & 10.97 & 3.09 & 19.94 & 9.31 & 19.23 & 17.15 & NS \\
\hline Tiller plant ${ }^{-1}$ & 7.20 & 7.20 & 7.80 & 8.75 & NS & 7.00 & 6.75 & 6.60 & 8.25 & NS \\
\hline Spike Length (cm) & 9.65 & 10.77 & 9.67 & 9.31 & 0.86 & 9.63 & 8.54 & 9.40 & 8.00 & NS \\
\hline Days to Heading & 57.30 & 61.00 & 55.60 & 59.30 & 2.18 & 58.25 & 61.70 & 56.00 & 60.00 & NS \\
\hline WUE $\left(g \cdot \mathrm{kg}^{-1}\right)$ & 2.53 & 2.75 & 2.42 & 2.78 & NS & 2.28 & 3.05 & 2.55 & 2.86 & NS \\
\hline $\mathrm{ABA}\left(\mathrm{ng} \cdot \mathrm{g}^{-1}\right)$ & 26.14 & 39.12 & 30.93 & 36.30 & NS & 62.16 & 36.94 & 96.81 & 53.01 & NS \\
\hline
\end{tabular}

$\mathrm{LSD}_{0.05}=$ Differences between the values within a row that are narrower than LSD are not statistically different at 0.05 probability level. NS $=$ non-significant at 0.05 probability level. 
significantly different among the lines. Numerically, plant height of 1RS.1BL decreased about 30\% when exposed to water stressed condition followed by Pavon76, 1RS.1DL, and 1RS.1AL. The 1RS translocation consistently reduced plant height; however, statistical significance was seen only for well watered treatment in 2011. Height was also affected by water regime in both years. When exposed to water limiting conditions, the most detrimental height effect was seen on 1RS.1AL with more than $7 \mathrm{~cm}$ reduction. This finding was consistent with the findings of a study done by Ehdaie et al. [10], where 1RS.1AL was noted the tallest under a well water condition, but in a water stressed condition Pavon76 was noted to be the tallest. The 1RS.1AL produced the highest biomass (root and shoot) in both water regimes in 2011, however, the grain yield was not increase proportionately, thus the low harvest index (Table 3). The STI of lines ranged from 0.42 (1RS.1AL) to 0.66 (1RS.1BL) in 2011 whereas in 2012 the range was from 0.16 (1RS.1AL) to 0.44 (1RS.1BL). The STI values clearly suggest that translocation 1RS.1BL copes water stress better than other lines. In 2011, the 1RS.1BL showed the highest biomass in both treatments, which suggests that this line consistently partitioned its photosynthates to grain production. The root biomass showed positive trend with shoot biomass under both water regimes, which suggests that increasing the performance of one trait does not necessarily hinder the other trait. This also suggests that a good shoot system is may produce and provide necessary assimilates needed to develop a healthy root system. However, increasing root biomass does not necessarily increases the grain yield. A study done on Arabidopsis (A. thaliana) and its mutants reported that inhibition of lateral root development is a distinctive drought adaptive response [27]. This could be the reason why 1RS.1BL produced higher grain yield despite producing lower root biomass. Further study with focusing more than one aspect of root system may be required to consolidate this finding.

In 2012, the tested lines did not show significant differences for the measured traits within well water treatment, whereas in drought treatment, lines could be statistically distinguished for only spike per plant and dry root biomass (Table 4). Non-significant values for majority of lines in the second year could be due to high variations within measurements taken for each line for these traits. In the second year, plants were grown in plastic hoop house and due to prolonged cold and cloudy days in late fall 2012 and early winter 2013, plants stayed green for longer period of time which subsequently delayed maturity of all lines. This might have contributed to steep variations across replications of the measured trait. From the numeric perspective, like the first year, highest amount of biomass in well water treatment was produced by 1RS.1AL. Also, harvest index of 1RS.1BL was consistently higher than its counterparts in both treatments. Unexpectedly, in 2012 water stress treatment, 1RS.1DL produced the highest total biomass associated with highest number of spike per plant. However, the grain yield was the least. This could be due to unfilled spikes. We used PROC REG in SAS to observe association of dry shoot biomass with grain. There was significant correlation between the two only when the average values of each line were used and not when the whole data set was used. The correlation result was not conclusive due to having only four points to infer. Therefore, the result is not presented.

Table 4. Mean and Least Significant Difference (LSD) values of all traits measured in 2012 for Pavon76 and its rye translocation lines grown under well-water and water stress (drought) conditions.

\begin{tabular}{|c|c|c|c|c|c|c|c|c|c|c|}
\hline \multirow{3}{*}{ Trait } & \multicolumn{10}{|c|}{2012} \\
\hline & \multicolumn{5}{|c|}{ Well-Watered } & \multicolumn{5}{|c|}{ Drought } \\
\hline & Pavon76 & 1AL & 1BL & 1DL & $\mathbf{L S D}_{0.05}$ & Pavon76 & 1AL & 1BL & 1DL & LSD \\
\hline Plant Height (cm) & 54.80 & 54.42 & 52.36 & 49.84 & NS & 53.14 & 47.74 & 52.82 & 50.00 & NS \\
\hline Spike plant ${ }^{-1}$ & 9.20 & 12.60 & 8.60 & 10.00 & NS & 5.80 & 3.40 & 5.20 & 7.40 & 2.37 \\
\hline Dry Root (g) & 2.04 & 2.76 & 1.82 & 1.85 & NS & 0.80 & 0.48 & 0.68 & 1.00 & 0.36 \\
\hline Dry shoot (g) & 13.54 & 15.04 & 12.74 & 14.26 & NS & 7.48 & 6.00 & 7.40 & 8.56 & NS \\
\hline Grain wt. (g) & 1.66 & 1.40 & 2.42 & 2.32 & NS & 0.32 & 0.44 & 0.92 & 0.24 & NS \\
\hline Harvest Index & 12.53 & 9.46 & 19.05 & 16.74 & NS & 3.97 & 5.95 & 12.77 & 2.69 & NS \\
\hline $\mathrm{ABA}\left(\mathrm{ngg}^{-1}\right)$ & 42.81 & 49.93 & 58.53 & 64.29 & NS & 67.82 & 94.31 & 50.92 & 141.50 & NS \\
\hline
\end{tabular}

$\mathrm{LSD}_{0.05}=$ Differences between the values within a row that are narrower than LSD are not statistically different at 0.05 probability level. NS $=$ non-significant at 0.05 probability level. 


\subsection{Physiological Trait}

One of the major physiological responses of plants when exposed to water deficit environment is the elevation of ABA content. In our study, the lines showed inconsistent levels of ABA in water stress treatment. In 2011, the 1RS.1BL had the highest level of ABA whereas in 2012, the highest level was observed for 1RS.1DL (Table 4). Westgate et al. [28] reported up to 30 folds increase in wheat leaf ABA content when grown in drought condition. In our study, even though there was significant influence of water regime on ABA content, the variation was not as much. The differences between average ABA content among the tested lines, especially in water stress treatments (both years) are numerically very wide yet not statistically different when considered within each water regime, which could be due lower number of replications and missed values which greatly reduced the power to predict the statistical significance. In the first year, two leaf samples from each line were evaluated where two lines had only one measurement determined due to missing analytical error. In our study, leaf ABA concentration was significantly influenced by the Studies on maize showed that root and leaf ABA concentration during drought plays a vital role in drought adaptive response of the crop and argued that chromosome loci controlling the ABA content is also responsible for other drought related traits such as stomatal conductance, root architecture, leaf temperature, etc. [13] [14] [29]. In our study, 1RS.1BL consistently produced higher ABA concentration than other lines which could have played role in its elevated grain yield under water stressed conditions.

\section{Conclusion}

The results from this study show that 1RS rye chromosomal translocation to 1BL of wheat is more suited to tolerate moisture stress than the other chromosomal translocations tested. When exposed to water stressed condition, the 1RS.1BL translocation line accumulated more of its photosynthates on grain than other plant parts. The 1RS.1AL consistently produced higher number of spikes and total biomass under the well watered condition in both years, but the spike number (hence the grain weight) significantly decreased under moisture limiting conditions. This suggests that the 1AL translocation is desirable if the goal of a breeding program is to develop lines for environments that are not likely to be exposed to severe moisture deficit. Our greenhouse study attempted to identify suitable rye chromosome (1RS) translocation with the aim of developing lines that are more adaptive to moisture stress conditions. Greenhouse studies do not always simulate the natural growing conditions for plants. Therefore, in order to further consolidate our findings, a field study is essential. In addition, the use of wheat in daily food products may demand the testing of translocation lines for quality attributes within a breeding program. Results from our study show that drought adaptation is a complex trait and may involve several systems within the plant to function as a whole.

\section{Acknowledgements}

Authors wish to acknowledge Center of Excellence on Drought Tolerance Research (CEDTR) at South Dakota State University for providing funding for the study. Likewise we also would like to thank Dr. Adam J. Lukaszewski at University of California, River side for providing plant materials for the study.

\section{References}

[1] Manschadi, A.M., Hammer, G.L., Christopher, J.T. and de Voil, P. (2008) Genotypic Variation in Seedling Root Architectural Traits and Implication for Drought Adaptation in Wheat (Triticum aestivum L.). Plant and Soil, 303, 115-129. http://dx.doi.org/10.1007/s11104-007-9492-1

[2] Gallagher, J.N., Biscoe, P.V. and Scott, R.K. (1975) Barley and Its Environment. V. Stability of Grain Weight. Journal of Applied Ecology, 12, 319-336. http://dx.doi.org/10.2307/2401735

[3] Ehdaie, B., Hall A.E., Farquhar, G.D., Nguyen, H.T. and Waines, J.G. (1991) Water-Use Efficiency and Carbon Isotope Discrimination in Wheat. Crop Science, 31, 1282-1288. http://dx.doi.org/10.2135/cropsci1991.0011183X003100050040x

[4] Blum, A. (2000) Effective Use of Water (EUW) and Not Water-Use Efficiency (WUE) Is the Target of Crop Yield Improvement under Drought Stress. Field Crops Research, 112, 119-123. http://dx.doi.org/10.1016/j.fcr.2009.03.009

[5] Starzycki, S. (1976) Diseases, Pests and Physiology of Rye. In: Bushuk, W., Ed., Rye: Production, Chemistry and Technology, American Association of Cereal Chemists, St. Paul, 27-61. 
[6] Koebner, R.M.D. and Shepherd, K.W. (1988) Isolation and Agronomic Assessment of Allosyndetic Recombinants Derived from Wheat/Rye Translocation 1DL.1RS, Carrying Reduced amounts of Rye Chromatin. In: Miller, T.E. and Koebner, R.M.D., Eds., Proceedings of the 7th International Wheat Genetics Symposium, Cambridge, 13-19 July 1988, Institution of Plant Science Research, 343-348.

[7] McKendry, A.L., Taque, D.N. and Ross, K. (2001) Comparative Effects of 1BL.1RS and 1AL.1RS on Soft Red Winter Wheat Milling and Baking Quality. Crop Science, 41, 712-720. http://dx.doi.org/10.2135/cropsci2001.413712x

[8] Villareal, R.L., del Toro, E., Rajaram, S. and Mujeed-Kazi, A. (1996) The Effect of Chromosome 1AL/1RS Translocation on Agronomic Performance of 85 F2-Derived F6 Lines from Three Triticum aestivum L. Crosses. Euphytica, 89, 363-369.

[9] Rabinovich, S.V. (1998) Importance of Wheat-Rye Translocation for Breeding Modern Cultivars of Triticum aestivum L. Euphytica, 100, 323-340.

[10] Ehdaie, B., Whitkus, R.W. and Waines, J.G. (2003) Root Biomass, Water-Use Efficiency, and Performance of WheatRye Translocations of Chromosome 1 and 2 in Spring Bread Wheat "Pavon”. Crop Science, 43, 710-717. http://dx.doi.org/10.2135/cropsci2003.0710

[11] Ludlow, M.M. and Muchow, R.C. (1990) A Critical Evaluation of Traits for Improving Crop Yields in Water-Limited Environments. Advances in Agronomy, 43, 107-153. http://dx.doi.org/10.1016/S0065-2113(08)60477-0

[12] Ehdaie, B., Layne, A.P. and Waines, J.G. (2012) Root System Plasticity to Drought Influences Grain Yield in Bread Wheat. Euphytica, 186, 219-232. http://dx.doi.org/10.1007/s10681-011-0585-9

[13] Sanguineti, M.C., Tuberosa, R., Landi, P., Salvi, S., Maccaferri, M., Casarini, E. and Conti, S. (1999) QTL Analysis of Drought-Related Traits and Grain Yield in Relation to Genetic Variation for Leaf Abscisic Acid Concentration in Field-Grown Maize. Journal of Experimental Botany, 50, 1289-1297. http://dx.doi.org/10.1093/jexbot/50.337.1289

[14] Giuliani, S., Sanguineti, M.C., Tuberosa, R., Bellotti, M., Salvi, S. and Landi, P. (2005) Root-ABA1, a Major Constitutive QTL, Affects Maize Root Architecture and Leaf ABA Concentration at Different Water Regimes. Journal of Experimental Botany, 56, 3061-3070. http://dx.doi.org/10.1093/jxb/eri303

[15] Graybosch, R.A., Lee, J.H., Peterson, C.J., Porter, D.R. and Chung O.K. (1999) Genetic, Agronomic and Quality Comparisons of Two 1AL.1RS. Wheat-Rye Chromosomal Translocations. Plant Breeding, 118, 125-130. http://dx.doi.org/10.1046/j.1439-0523.1999.118002125.x

[16] McKendry, A.L., Tague, D.N., Finny, P.L. and Miskin, K.E. (1996) Effect of 1BL.1RS on Milling and Baking Quality of Soft Red Winter Wheat. Crop Science, 36, 848-851.

[17] Villareal, R.L., Rajaram, S., Mujeeb-Kazi, A. and Del Toro, E. (1991) The Effect of Chromosome 1B/1R Translocation on the Yield Potential of Certain Spring Wheats (Triticum aestivum L.). Plant Breeding, 106, 77-81. http://dx.doi.org/10.1111/j.1439-0523.1991.tb00482.x

[18] Villareal, R.L., del Toro, E., Mujeeb-Kazi, A. and Rajaram, S. (1995) The 1BL/1RS Chromosome Translocation Effect on Yield Characteristics in a Triticum aestivum L. Cross. Plant Breeding, 114, 497-500. http://dx.doi.org/10.1111/j.1439-0523.1995.tb00843.x

[19] Lukaszewski, A.J. (1997) Further Manipulation by Centric Misdivision of the 1RS.1BL Translocation in Wheat. Euphytica, 7, 1-5.

[20] Bengough, A.G., Gordon, D.C., Al-Menaie, H., Ellis, R.P., Allan, D., Keith, R., Thomas, W.T.B. and Forster, B.P. (2004) Gel Observation Chamber for Rapid Screening of Root Traits in Cereal Seedlings. Plant and Soil, 262, 63-70. http://dx.doi.org/10.1023/B:PLSO.0000037029.82618.27

[21] Large, E.C. (1954) Growth Stages in Cereals Illustration of the Feekes Scale. Plant Pathology, 3, 128-129. http://dx.doi.org/10.1111/j.1365-3059.1954.tb00716.x

[22] Ehdaie, B. (1995) Variation in Water-Use Efficiency and its Components in Wheat: II. Pot and Field Experiments. Crop Science, 35, 1617-1626. http://dx.doi.org/10.2135/cropsci1995.0011183x003500060017x

[23] SAS Institute (2008) The SAS System for Windows. Release 9.2., Cary.

[24] Nakamoto, T. and Oyanagi, A. (1996) The Configuration of the Seminal Roots of Triticum aestivum L. (Poaceae). Journal of Plant Research, 109, 375-380. http://dx.doi.org/10.1007/BF02344552

[25] Manschadi, A.M., Christopher, J., de Voil, P. and Hammer, G.L. (2006) The Role of Root Architectural Traits in Adaptation of Wheat to Water-Limited Environments. Functional Plant Biology, 33, 823-837. http://dx.doi.org/10.1071/FP06055

[26] Christopher, J., Christopher, M., Jennings, R., Jones, S., Fletcher, S., Borrell, A., Manschadi, M., Jordan, D., Mace, E. and Hammer, G. (2013) QTL for Root Angle and Number in a Population Developed from Bread Wheats (Triticum aestivum) with Contrasting Adaptation to Water-Limited Environments. Theoretical and Applied Genetics, 126, 15631576. http://dx.doi.org/10.1007/s00122-013-2074-0 
[27] Xiong, L., Wang. R., Mao, G. and Koczan, J.M. (2006) Identification of Drought Tolerance Determinants by Genetic Analysis of Root Response to Drought Stress and Abscisic Acid. Plant Physiology, 142, 1065-1074. http://dx.doi.org/10.1104/pp.106.084632

[28] Westgate, M.E., Passioura, J.B. and Munns, R. (1996) Water Status and ABA Content of Floral Organs in Drought Stressed Wheat. Australian Journal of Plant Physiology, 23, 763-772. http://dx.doi.org/10.1071/PP9960763

[29] Tuberosa, R., Sanguineti, M.C., Landi, P., Salvi, S., Cassarini, E. and Conti, S. (1998) RFLP Mapping of Quantitative Trait Loci Controlling Abscisic Acid Concentration in Leaves of Drought-Stressed Maize (Zea mays L.). Theoretical and Applied Genetics, 97, 744-755. http://dx.doi.org/10.1007/s001220050951 
Scientific Research Publishing (SCIRP) is one of the largest Open Access journal publishers. It is currently publishing more than 200 open access, online, peer-reviewed journals covering a wide range of academic disciplines. SCIRP serves the worldwide academic communities and contributes to the progress and application of science with its publication.

Other selected journals from SCIRP are listed as below. Submit your manuscript to us via either submit@scirp.org or Online Submission Portal.
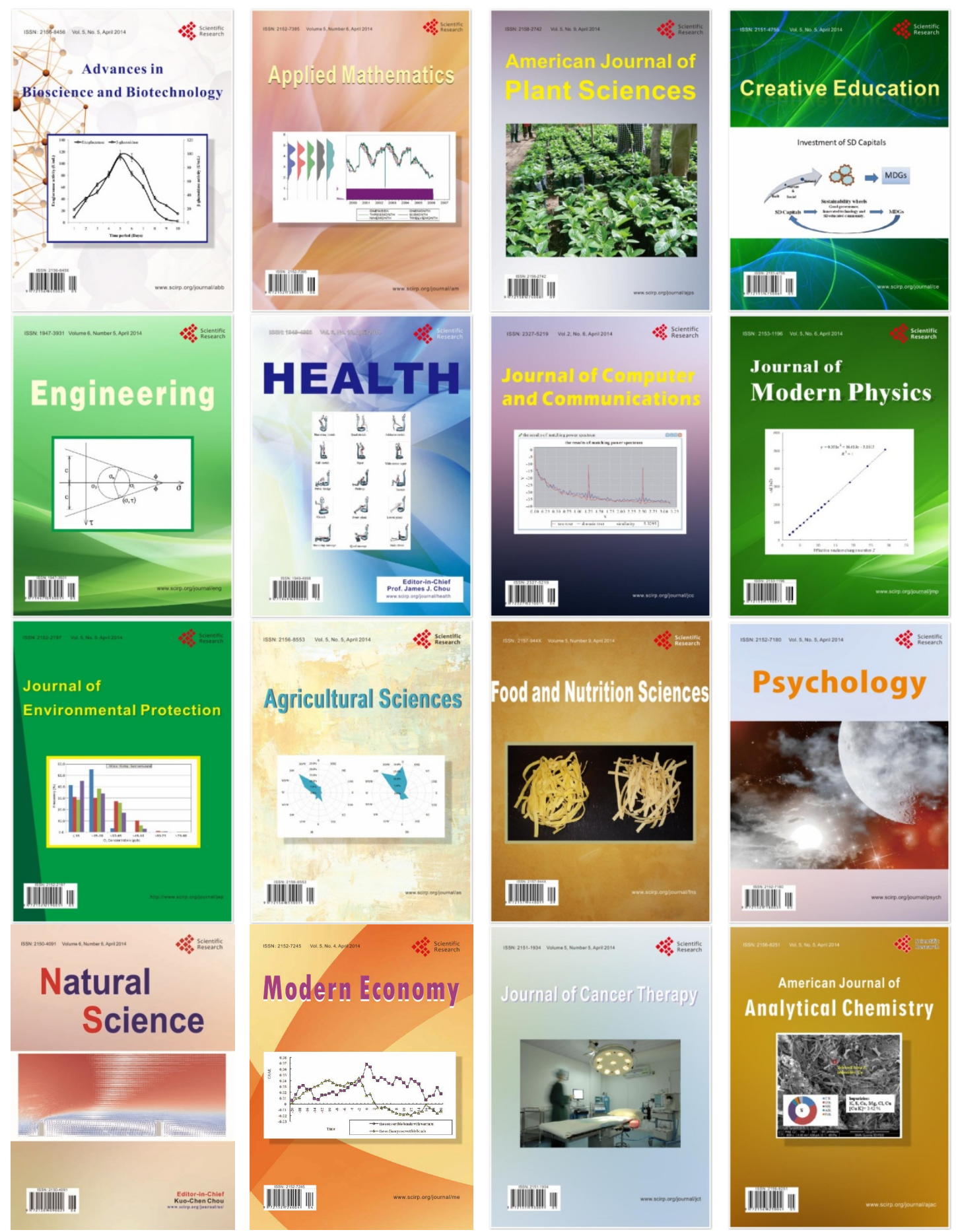